Rev. Elet. em Gestão, Educação e Tecnologia Ambiental (e-ISSN: 2236-1170)

\title{
AGRICULTURA: DOS POVOS NOMADES AOS COMPLEXOS AGROINDUSTRIAIS
}

\author{
Alana Roos' \\ ${ }^{1}$ Mestranda do Curso de Geografia da Universidade Federal de Santa Maria - UFSM. PPGEO. E-mail: \\ alanaroos@bol.com.br
}

\section{RESUMO}

A agricultura é uma grande rede de sistemas integrados que buscam o melhoramento de suas atividades, mas para chegar a esse nível muitos fatos ocorreram e ocasionaram o desenvolvimento agrícola, tornando-se assim uma atividade complexa $\mathrm{O}$ objetivo principal deste artigo é ponderar acerca do processo pelo qual a agricultura se configurou, desde os primeiros atos agrícolas até os complexos agroindustriais, além de compreender os processos que ocasionaram a evolução agrícola, bem como analisar quais fenômenos foram necessários para que tal fato acontecesse. Para explicar a evolução agrícola do Brasil foi necessária, primeiramente, uma pesquisa bibliográfica, que inclui livros que abordam desde o surgimento dos primeiros povoados na beira dos rios da Europa, até as obras que mencionam a formação dos Complexos Agroindustriais, para após escrever um artigo fundamentado. A agricultura, dos povos nômades aos Complexos Agroindustriais, que se pretende abordar nesse artigo, sofreu diversas modificações, enfrentando diferentes processos para o seu avanço, com várias relações que envolvem, não somente, espaço rural, mas também as questões políticas, técnicas, sociais e de mercado. Para a compreensão evolutiva da agricultura no Brasil, todos estes aspectos são necessários, porque não se pode visualizar tal fato sem abranger tais ocorrências, estas que foram indispensáveis para a evolução agrícola brasileira. Com isso vê-se a complexidade da agricultura, pois esta envolve muitas ações, sendo um emaranhado de tais relações, que por muitas vezes, é um processo que visa interesses que não são de importância para a agricultura e sim de interesse a pessoas e/ou a fatores que visam mais o lucro do que a produção.

Palavras-chaves: espaço agrícola; agroindústrias; avanço tecnológico; capitalismo.

\section{ABSTRACT}

Agriculture is a large network of integrated systems that seek to improve their activities, but to reach that level many events occurred and caused agricultural development, making it a complex activity The main objective of this paper is to ponder the process by which agriculture is set from the first agricultural acts to the agroindustrial complex, and understanding the processes that led to the development of agriculture, as well as analyze phenomena which were necessary for this to actually happen. To explain the evolution of agriculture in Brazil was necessary, first, a literature search, which includes books which range from the emergence of early settlements along the rivers of Europe, to the works that mention the formation of the Agroindustrial Complex, after writing an article for reasoned. The agriculture, nomadic peoples to Agroindustrial Complex, which aims to examine in this article, has undergone various modifications, facing different processes for their advance, with several relations involving not only, rural areas, but also the political, technical, social and market. To understand evolution of agriculture in Brazil, all these aspects are necessary, because you can not view this fact would not cover such instances, these were indispensable for the Brazilian agricultural developments. With it shows the complexity of agriculture, as this 
involves many actions, and such a tangle of relationships, which often is a process that aims to interests that are not of importance to agriculture, but of interest to persons and / or factors that aim to profit more than production.

Keywords: agricultural land, agro-industries, technological advances; capitalism.

\section{INTRODUÇÃO}

Os primeiros vestígios da agricultura são estabelecidos no período neolítico, mais conhecido como período da pedra polida, a cerca de doze mil anos, quando os seres humanos notaram que os grãos poderiam ser semeados. Com isso os povos se tornaram sedentários, pois tal prática permitiu a ampliação da oferta de alimentos para as pessoas. Porém como os vestígios da agricultura são anteriores a escrita, não se tem certeza do período exato do seu início (Mazoyer e Roudart, 1998).

A agricultura é um processo muito antigo, proveniente de inúmeras observações feitas pelos povos que habitavam o globo terrestre, podendo ser considerado um passo para a evolução da raça humana. Foi somente a partir desses povos que se iniciou o método de cultivo da terra, pressuposto que não havia nenhuma técnica para a cultura do solo. Silva (1998b, p. 4), afirma que "a industrialização da agricultura implica a passagem de um sistema de produção artesanal a um sistema em base manufatureira". Para tal Graziano da Silva nos aponta que [...]

[...] a industrialização do campo é um momento específico do processo de modernização, a reunificação agricultura-indústria num patamar mais elevado que do simples consumo de bens industriais pela agricultura. É o momento da modernização a partir do qual a indústria passa a comandar a direção, as formas e o ritmo da mudança na base técnica agrícola, o que ela só pode fazer após a implantação do D1 para a agricultura no país (SILVA, 1982c, p.32).

Como o autor nos aponta é a diversificação do sistema produtivo que se coloca diante dos novos paradigmas agrícolas que se estabelecem no ramo da agricultura, uma vez que este acompanha a evolução humana, com isso, diversos autores dividem a agricultura em três etapas: a Antiga, a Moderna e a Contemporânea. Silva apud Marx (1969, p.2) assegura que "o modo de produção capitalista completa a ruptura dos laços primitivos que no começo uniam a agricultura e a manufatura". Vê-se com tal fato que a agricultura passa de uma fase a outra, mas ainda assim encontram-se as fases anteriores misturadas com as mais atuais, pelo fato de que esse processo, de mudanças, não estipula marcos para acontecer ou para deixar de existir.

Com o avanço tecnológico, vários processos foram estabelecidos na agricultura, para melhorar a técnica e aumentar a produção, visando o aumento da renda diante do sistema do capitalismo. Esses artifícios representaram uma ruptura no pensamento agrícola do Brasil, demonstrando que o espaço rural poderia ter valor na economia nacional e até mesmo mundialmente. Diante de tal situação Kautsky afirma que [...] 
Rev. Elet. em Gestão, Educação e Tecnologia Ambiental (e-ISSN: 2236-1170)

[...] o camponês deixa de ser, pois, o senhor na sua exploração agrícola. Esta se torna um apêndice da exploração industrial por cujas conveniências deve orientar-se (...). Frequentemente, também cai sob a dependência técnica da exploração industrial (...). Como nos demais setores da sociedade capitalista, a indústria acaba por vencer a agricultura (...). A indústria constitui a mola não apenas de sua evolução mas ainda da evolução agrícola. Vimos que foi a manufatura urbana que dissociou, no campo, a indústria e a agricultura, que fez do rural um lavrador puro, um produtor dependente dos caprichos do mercado, que criou a possibilidade de sua proletarização (...). Foram criadas assim as condições técnicas e científicas da agricultura racional e moderna, a qual surgiu com o emprego de máquinas e deu-lhe, pois, superioridade da grande exploração capitalista sobre a pequena exploração camponesa (KAUTSKY, 1980, p. 281-318).

Fica muito evidente que a agricultura brasileira é diversificada, Mazoyer e Roudart (1998), descrevem esse processo como sendo complexo e variado apresentando várias esferas das quais se podem extrair muitos artifícios, ou seja, o sistema agrícola do Brasil é um emaranhado de procedimentos que estão favorecendo sempre uma parcela da população. O campo evolui diante das novas práticas que são inseridas no seu espaço, assim é necessário aumentar a produção para cobrir os custos da produção, uma vez que para aumentar a produção novos investimentos são necessários.

Este artigo busca compreender os processos que fazem parte da agricultura brasileira, até chegar-se a formação dos Complexos Agroindustriais (CAIs). É através dos procedimentos que ocorreram no espaço rural que se estabeleceram novas metodologias de trabalho no campo. É através da análise e apreensão das características da evolução agrícola que se pode então verificar quais foram às causas que conseqüências que foram necessárias para se chegar aos CAls.

Portanto esse artigo pretende ponderar acerca da evolução agrícola do Brasil, desde os povos nômades até a formação dos Complexos Agroindustriais (CAIs).

\subsection{0 que são os Complexos Agroindustriais (CAls)}

Os Complexos Agroindustriais podem ser entendidos como uma grande articulação interna formado pelas atividades agropecuárias e industriais que transformam as matérias-primas. Assim o termo Complexo Agroindustrial tem sido utilizado para rotular articulações entre os setores agrícola e industrial que vêm ocorrendo na agricultura brasileira. Entende-se, com isso, que Complexo Agroindustrial é [...]

[...] o conjunto de relações entre indústria e agricultura na fase em que esta mantém intensas conexões para trás, com a indústria para a agricultura e para frente, com as agroindústrias e outras unidades de intermediação que exercem impactos na dinâmica agrária. O Complexo Agroindustrial é uma forma de unificação das relações entre os grandes departamentos econômicos com os ciclos e as esferas de produção, distribuição e consumo, relações estas associadas às atividades agrárias (MÜLLER, 1989, p.41). 
Rev. Elet. em Gestão, Educação e Tecnologia Ambiental (e-ISSN: 2236-1170)

São vários os processos que ocasionaram a formação dos CAls, ou seja, os Complexos Agroindustriais são resultado de um denso procedimento de transformação agrícola, esses complexos não envolvem somente processos de caráter agrícola, mas também econômico, político e cultural.

Muitos estudiosos, dos quais podemos citar Graziano da Silva, Kageyama e Martine contribuíram para nos situar no tempo-espaço que envolveu e envolve essa passagem dos povos nômades aos CAls. Com isso, tem-se o envolvimento dessa substituição da agricultura manual, da economia natural a modernização da agricultura, a industrialização do processo agrícola.

Diante desses aspectos a constituição dos CAls em nosso país envolveu a industrialização de máquinas, equipamentos e insumos, a modernização e expansão do sistema agroindustrial.

Os Complexos Agroindustriais constituíram-se assim em um dos agentes de transformação do setor agropecuário brasileiro. Ressalta-se com tal fato a integração de capitais na agricultura brasileira, o capital industrial, o capital do Estado e o capital de grandes proprietários rurais.

Assim a noção de Complexo Agroindustrial resulta do consentimento da existência de um complexo rural na agricultura brasileira. Sendo que a principal transformação da agricultura brasileira está presente diante de um processo histórico, ou seja, da passagem do complexo rural manual para uma dinâmica comandada pelos complexos agroindustriais (CAls).

\section{REFERENCIAL TEÓRICO}

Os povos nômades foram os primeiros a desenvolverem uma técnica primitiva de agricultura, visto que eles descobriram que as sementes das frutas que colhiam geravam novas fontes de alimento, com isso os primeiros sinais da agricultura se estabeleciam. Esses povos deixaram de ser nômades e passaram a ser sedentários, visto que os grãos dos alimentos forneciam os alimentos dos quais necessitavam, se introduzia assim o cultivo do solo. (Mazoyer e Roudart, 1998). Também através dos povos primitivos que se descobriram os primeiros instrumentos agrícolas como machadinhas e pás, pois para aumentar as fontes de alimento era imprescindível arar a terra.

Ao longo dos anos novas técnicas de se fazer uso da terra foram sendo descobertas e desenvolvidas pelo mundo inteiro. Muitos povos domesticaram plantas e animais para poderem usufruir dos produtos que necessitavam para sobreviver e aumentar a quantidade, visto que, ao se estabelecerem em um local permanente a população aumentou, demandando um aumento no consumo de alimentos. De acordo com Mazoyer e Roudart o ser humano [...]

[...] apenas conseguia sobreviver à custa da colheita de produtos vegetais e da captura dos animais mais acessíveis, em meios pouco hostis ou dispondo de sítios protetores. Com poucos conhecimentos, pobre em instintos mas imensamente educável, o seu principal trunfo residia então na variedade dos climas, dos regimes alimentares e dos modos de vida que Ihe podiam convir. O homem é eclético, onívoro e adaptável... estas são as suas primeiras vantagens (MAZOYER e ROUDART, 1998, p.25). 


\section{Rev. Elet. em Gestão, Educação e Tecnologia Ambiental (e-ISSN: 2236-1170)}

Vê-se com isso o início da agricultura no mundo inteiro, sendo que muitos povos deixaram o nomadismo para se estabelecerem em um determinado local, após aprenderem as técnicas mais primitivas do uso do solo e de cultivo.

No Brasil o uso da terra configura-se inicialmente através de povos indígenas que se encontravam no país e que se utilizavam das técnicas primitivas do uso do solo (Prado Jr, 1969). Esses povos utilizavam de instrumentos artesanais para arar o solo e do método de queimadas da vegetação nativa para constituírem pastagens e suas próprias aldeias. Após o descobrimento do Brasil no ano de 1500, a agricultura brasileira iniciou-se no nordeste do país, em que as primeiras navegações chegaram por volta do século XVI, estabelecendo então as Capitanias Hereditárias e iniciando o plantio da cana de açúcar.

Inicialmente a atividade agrícola brasileira era praticada em forma de monoculturas, distribuídas em grandes latifúndios, ocupando a mão de obra escrava e sendo concentrada nas mãos dos donos das plantações, monopolizando o sistema. Neste período a agricultura não estabelecia grande expressividade, devido ao fato de ter-se uma cultura de subsistência para a população da própria região ou até mesmo visando somente os donos dos latifúndios. Como nos afirma Prado Jr et al [...]

[...] o essencial da estrutura agrária brasileira legada pela colônia se encontrava assim como que predeterminada no próprio caráter e nos objetivos da colonização. A grande propriedade fundiária constituiria a regra e elemento central e básico do sistema econômico da colonização, que precisava desse elemento para realizar os fins a que se destinava (PRADO JR et al, 1969, p.10).

Através das plantações de café e com a mineração, no século XVIII, se iniciou a produtividade agrícola do Brasil, ou seja, a agricultura passava a estabelecer novas metas, visando o aumento da renda e ampliando o processo agrícola, e foi somente no século XIX que estes produtos estabeleceram uma grande expressividade na atividade agrícola do Brasil, devido à valorização de tais produtos nos mercados internacionais. Novas técnicas e novos instrumentos agrícolas foram sendo acrescentados, para cada vez mais desenvolver o sistema agrícola e aumentar a renda.

O café constitui seu auge entre os anos de 1890 a 1930, depois da introdução do trabalho livre assalariado, mas assim como a cana de açúcar teve declínio com a implementação do café e da mineração como principais produtos brasileiros, o café começa a perder força por volta da década de 1930 com a crise ocorrida no país. Depois desse período teve-se a integração dos mercados nacionais, com a fase da industrialização pesada, na qual foram implantados maquinários pesados e novas fontes de cuidado com a terra.

A agricultura moderna estabeleceu novas fronteiras agrícolas exercendo papel fundamental para novos avanços no que diz respeito à agricultura brasileira. Esta intensificou o uso de maquinário, de novas técnicas de cultivo do solo e demais avanços que puderam fornecer novidades no campo brasileiro.

Novas formas de cultivos foram necessárias para a complementação da economia brasileira e mediante os avanços tecnológicos. Nesse ponto encontra-se a modernização da agricultura, sendo que o sistema agrícola de aproveitamento da terra melhorou imensuravelmente. De acordo com Prado Jr et al (1969) foi o melhoramento desse sistema que possibilitou a implantação de complexos agroindustriais. 


\section{Rev. Elet. em Gestão, Educação e Tecnologia Ambiental (e-ISSN: 2236-1170)}

Conforme a população brasileira foi aumentando, necessitando assim de mais produtos do setor primário, e conforme o sistema capitalista foi avançando, os CAls foram ganhando expressividade justamente por aliar esses pequenos produtores ao sistema do capitalismo e com tal fato os produtores puderam inserir-se no mercado internacional de produção, vendendo seus produtos e subprodutos em, praticamente, todos os mercados, sejam nacionais ou internacionais.

Como nos afirma Silva (1998, p. 29), "a idéia de que os CAls são um fato recente na economia brasileira, um fenômeno dos anos 70". Vê-se com tal citação que a elaboração de novos conceitos agrários é recente, estabelecendo um processo inovador e muito novo. Muitos ainda estudam a formação dos CAls e verificam quanto aos seus aspectos de funcionamento. Ainda segundo Silva $(1998$, p.35) "enquanto o complexo rural e posteriormente o complexo cafeeiro paulista podiam ser considerados grandes unidades da agricultura, hoje temos que pensar nos vários complexos, que adquirem formas e graus de inter-relacionamento distintos em cada caso concreto".

Essas organizações tornaram-se operações especializadas em vender seus produtos, criaram-se funções bem definidas para cada setor desses complexos, sendo que cada setor desempenha sua função mediante o bem maior dos produtores que estão vinculados aos CAls.

Cabe destacar que os avanços ocorridos no espaço rural foram fonte para muitos produtores melhorarem suas vidas e a sua produção, os CAls são um exemplo de tal processo, pois os produtores pertencentes a esses complexos se ajudam reciprocamente, porém não estabelecem relações com que não pertence ao seu CAls.

Poderão ter-se a introdução de novas técnicas no espaço agrário do Brasil e do mundo, estas que serão impostas no mercado pela demanda de produtos que são indispensáveis para suprir as necessidades da população mundial e será preciso a atualização de todas as formas de produção agrária, ou seja, o avanço tecnológico ajuda e ajudou muito para o avanço agrícola, mas também forneceu subsídios para aumentar a demanda de produtos primários.

\section{CONSIDERAÇÕES FINAIS}

A agricultura, durante muito tempo, foi fonte de renda para muitas pessoas uma vez que esta foi à base econômica do país, quando estava sentada nos canaviais e na cafeicultura. $E$ também, esteve no centro de muitos conflitos, sejam eles econômicos, políticos, técnicos, financeiros e até mesmo históricos, sendo um desafio para muitos países. O processo agrícola envolveu muitos desafios para o Brasil, já que precisou modificar as técnicas de seu sistema agrário devido aos avanços do próprio sistema agrícola e pela implantação do sistema capitalista.

Que agricultura se espera ao se praticar inúmeros processos durante a evolução da mesma? É a da alta produtividade, com milhões de agricultores com máquinas motorizadas, mecanizados e por muitas vezes não especializados para a manipulação de tais máquinas, ocasionado, com isso, relações de trabalho, desigualdades sociais, políticas e econômicas.

Além da ocorrência de danos ao solo e aos recursos naturais utilizados, por que muitas vezes estas técnicas não são utilizadas por profissionais, isto é, são desenvolvidas por técnicos que não se encontram no campo e são, simplesmente, praticadas pelos agricultores, sem que estes tenham uma assistência técnica ou que sejam orientados como fazer uso dessas técnicas.

Em conclusão, o que se reflete no ramo das atividades agrícolas, é que sempre ocorreu a modificação no campo, e o que causa esta modificação da estrutura fundiária brasileira? Como se viu tal situação de mudança é de importância para a melhora na agricultura, pois sem tais avanços 
Rev. Elet. em Gestão, Educação e Tecnologia Ambiental (e-ISSN: 2236-1170)

tecnológicos não se poderia chegar-se ao desenvolvimento dos CAls e não teria essas novas técnicas agrícolas, mesmo que tais técnicas ocasionem danos ambientais. Esses danos seriam menores com uma política de regulação e cumprimento de regras para as atividades agrícolas e os agricultores recebessem maiores instruções e informações sobre o uso das técnicas agrícolas.

Enfim, a prodigiosa evolução brasileira da agricultura utilizou-se dos mais diversificados processos agrícolas para atingir os CAIs, desde a dominação das técnicas agrícolas pelos povos nômades até as técnicas mais avançadas de uso do solo, o ser humano fez uso de todos os procedimentos e técnicas que tinha ao seu alcance para fazer diversificar a agricultura brasileira e mundial, e assim chegar aos CAls.

Portanto podemos definir os CAls como sendo um conjunto de ações que englobam produção e a distribuição dos produtos rurais, considerando todas as operações necessárias para a exploração rural, juntamente com o armazenamento, o processamento e a distribuição dos produtos agrícolas e de seus subprodutos.

\section{REFERÊNCIAS}

KAGEYAMA, Ângela et al. O novo padrão agrícola brasileiro: do complexo rural aos complexos agro-industriais. UNICAMP, Campinas (SP), 1987.

KAUTSKI, K. A questão agrária. 3. ed. São Paulo: Proposta Editorial, 1980.

MARTINE, G. A trajetória da modernização agrícola: a quem beneficia? In: Questões agrárias, hoje \& democracia e sistema global. Revista de Cultura Política, n. 23, março 91, 1991.

MAZOYER, Marcel; ROUDART, Laurence. História das agriculturas do mundo: do neolítico à crise contemporânea. Lisboa: Instituto Piaget, 1998.

MOREIRA, Ruy. Formação do espaço agrário brasileiro. São Paulo: Brasiliense, 1990.

MÜLLER, Geraldo. As relações micro-macro e indústria agroalimentar: o poder econômico e a pesquisa em ciências sociais. Rascunho. Araraquara, n. 1, p. 1-53, jun. 1989.

SILVA, José Graziano da. A nova dinâmica da agricultura brasileira. 2. ed. Campinas, SP: UNICAMP. IE, 1998. (a).

SILVA, José Graziano da. A industrialização e a urbanização da agricultura brasileira. In: "O agrário paulista”. Revista da Fundação SEADE, vol. 7 (3), julho-setembro, 1993, São Paulo, p. 2 - 10. (b).

SILVA, José Graziano da. A modernização dolorosa: estrutura agrária, fronteira agrícola e trabalhadores rurais no Brasil. Rio de Janeiro: Zahar, 1982. (c).

SCHUH, G. Edward. O desenvolvimento da agricultura no Brasil. Rio de Janeiro: APEC, 1976.

PRADO JR, Caio; et al. Agricultura subdesenvolvida. Petrópolis, RJ: Editora Vozes, 1969. 